Third Meeting, January 11 th, 1884.

Thomas Muir, Esq, M.A., F.R.S.E., President, in the Chair.

\title{
Mathematical Models, chiefly of Surfaces of the Second Degree.
}

By Professor Chrystal, University of Edinburgh.

Professor Chrystal exhibited a number of models made of wood, cardboard, thread, and plaster of Paris, and made use of them for the exposition of some of the principal properties of the surfaces represented.

Theorem relating to the Sum of selected Binomial-Theorem Co-efficients.

By Professor TaIt, University of Edinburgh.

This theorem will be found in the Messenger of Mathematics for February 1884, vol. xiii., New Series, p. 154.

Professor Chrystal brought before the meeting a problem to which his attention had been drawn by $\mathrm{Mr} J$ ames Edward, M.A., B.Sc. The following is the problem, and Mr Edward's solution:-

Between two sides of a triangle to inflect a straight line which shall be equal to each of the segments of the sides between it and the base.

From $A B$, one of the sides of the given triangle $\triangle B C$, cut off $A D=A C$, and join $C D$. Divide $B C$, internally at $G$ and externally at $\mathrm{K}$, in the ratio of $\mathrm{AD}$ to $\mathrm{DC}$; on $\mathrm{GK}$ as diameter describe a circle cutting $\mathrm{CD}$ in $\mathrm{P}$. Join $\mathrm{BP}$; draw $\mathrm{PF}$ parallel to $\mathrm{BA}$ and meeting $A C$ in $F$; and draw FE parallel to $B P$ and meeting $A B$ in $E$.

The circle GPK is the locus of the vertices of all the triangles on the base $B C$, and having their sides in the ratio $B G: G C$; 


$\begin{array}{rlrl}\therefore & \mathrm{BP}: \mathrm{PC} & =\mathrm{BG}: \mathrm{GC}, \\ & & =\mathrm{AD}: \mathrm{DC}, \quad \text { (Construction) } \\ & =\mathrm{FP}: \mathrm{PC} ; \quad \text { (Eucl. VI. 4) } \\ \therefore \quad & \mathrm{BP} & =\mathrm{FP}, \text { and } \mathrm{BEFP} \text { is a rhombus. } \\ \text { But } & \mathrm{FC} & =\mathrm{FP}, \text { since } \mathrm{AC}=\mathrm{AD} ; \\ \therefore & \mathrm{BE} & =\mathrm{EF}=\mathrm{FC} .\end{array}$

Cor. 1. When triangle $\mathrm{ABC}$ is isosceles, $\mathrm{EF}$ is parallel to $\mathrm{BC}$.

Cor. 2. When $P$ moves up to D, F moves up to $A$. In this case, which is the limiting one for the point $P$ within the triangle, $\mathbf{B D}=\mathrm{DA}=\mathrm{AC}$. The limiting case therefore occurs when one of the sides is double of the other.

Cor. 3. When $A B$ is greater than twice $A C$, the point $\mathbf{P}$ is outside the triangle, $\mathrm{F}$ is on $\mathrm{CA}$ produced, and, as before, $\mathrm{BE}=\mathrm{EF}=\mathrm{FC}$.

Fourth Meeting, February 8th, 1884.

A. J. G. Barclay, Esq., M.A., Vice-President, in the Chair.

The Promotion of Research-A Presidential Address.

By Thomas Muir, M.A., F.R.S.E.

This paper has been printed by Mr Muir for distribution among the Members of the Society.

\section{Tllustrations of Harmonic Section.}

\section{By Hugh Hamilton Browning, M.A.}

[Abstract.]

The object of the paper was to draw attention to a few important and well known cases of the harmonic section of a straight line, and to show their application to one or two problems of interest, more especially the method of drawing tangents to a conic by the ruler only. The effort throughout was to secure clearness, brevity, and freshness of proof, coupled with purely geometrical treatment.

Among other propositions were the following:

(a) $\mathrm{O}, \mathrm{P}, \mathrm{V}, \mathrm{W}, \mathrm{X}$, are points in a straight line such that $\mathrm{PV}: \mathrm{PX}$ $=O V^{2}: O X^{2}$, and $O P=P W$; show that $O V$, OW, $O X$ are in 